\title{
The "gourmet" sausage factory: Keeping it human
}

\author{
Christiaan Willems \\ Creative Industries Faculty \\ Queensland University of Technology, Australia \\ c.willems@qut.edu.au
}

\begin{abstract}
Whilst tertiary institutions continue to invest heavily in the technological aspects of online Teaching \& Learning (T\&L), there does not appear to have been a commensurate investment in the "human" aspects of the use of the technology. Despite the broad recognition that teaching and learning materials need to be adapted for and to the onscreen medium, little attention appears to have been paid thus far to the actual people who are delivering it - who equally need to "adapt themselves" to that medium, in order to maximise the benefit of the technology by maximising the human communication skills of those using the online medium - as distinct from the technical skills required to drive and deliver the bits and bytes. The REdelivery Initiative was a direct response to that notion. This paper details - by way of a narrative of one of the workshop participants - that part of the process involving the professional development of academics specifically in and specifically for the digital, online, $T \& L$ context, in order to both illuminate and maximise the potential and opportunities afforded by the technology.
\end{abstract}

\section{Introduction}

REdelivery was an initiative instigated at the Queensland University of Technology to focus on ways for academics to repackage and literally, "redeliver" selected units ${ }^{1}$ through video. The overarching imperative was to make best use of technology through an entire re-examination and exploration of the pedagogy, practicality and effectiveness of delivering T\&L (teaching and learning) materials to students across a variety of platforms - particularly in view of the growing trend across the tertiary sector of non-attendance of lectures and tutorials (Massingham \& Herrington. 2006; Phillips et al. 2007).

The REdelivery team aimed to support academics, through customised workshops, in the effective use of appropriate, accessible technologies, in pedagogically appropriate ways to reduce their workloads without loss of quality in course experience or increased attrition. In doing so, in contrast to a "sausage-factory" approach, it was absolutely crucial to not only retain but indeed to highlight and maximise academics' individual approaches to their respective materials, contexts and students. Respecting that individuality whilst reconciling it with the need to produce significant numbers of video/online resources, represented an ongoing

\footnotetext{
${ }^{1}<$ https://mediawarehouse.qut.edu.au/QMW>
} 
challenge in budgetary, logistical, academic, professional development, and pedagogical terms, which needed to be continually balanced - the highest possible individualised quality against highest number of usable outputs. Not a sausage factory, rather a "Gourmet" Sausage Factory. This paper will begin with a brief background to online teaching and learning before describing the REdelivery workshops in detail. It concludes with a brief narrative of one participant, to be known as Academic X.

\section{Online Teaching \& Learning - The broader context}

Despite the growing interest among Australian universities in online teaching and learning, it is "surprisingly difficult to find a clear and precise definition of this multifaceted concept in the education literature" (Anderson, 2008, p. 55). More recently, Coaldrake and Stedman (2013) observed that: "in retrospect much of this talk greatly overestimated the capacity of the technology at the time and underestimated the complexity of the education process and student demand" ( $p$. 143). Thus the notion of online T\&L and academia's response to it continues to demand attention, analysis and action. It has been noted that:

Technology has had a significant impact on the way we teach and the way students learn... Twenty years ago, flexible learning meant using multiple whiteboard marker colours... Lectures were about lecturers talking and students listening. Students took notes! If you did not attend a lecture you knew you might miss out on something important. None of this is relevant today.

(Massingham \& Herrington, 2006, p. 85)

The bushfire-like speed with which technology consumes and renders obsolete almost everything in its path, causes one to consider how best to use that technology to advantage. And how quickly today's professional development undertaken, new skills developed, and technical knowledge acquired will be redundant by the time one has even properly grasped the concept - let alone become proficient enough with the current iteration/upgrade of a computer application to actually use its features to anything even approaching its full capacity by the time of the next upgrade. However the one certainty is that academics, whether on-campus or online and whether willingly or not, are inevitably, inescapably and inextricably bound up in this technical T\&L r/evolution because, "in reality, virtually every student uses online technologies... Online technology is changing both distance education ... and on-campus education" (Norton, Sonnemann, \& McGannon, 2013, p. 15).

Anecdotal computer industry evidence suggests that the vast majority of "average" computer non-specialists only ever use an estimated $20-30 \%$ of the full capabilities or features of any computer application. Whilst we might be enticed to purchase the very latest upgrade, or be forced to by withdrawal of technical support, the reality is that we will actually use, at best, only a third of any application's features. The expectation/assumption therefore that academics are "up with the latest technology" may be somewhat misguided. It seems therefore, 
at best, counterproductive and, at worst, irresponsibly wasteful of resources to not invest in the development of the professional skills of the people who use the technology. Ellis and Phelps (2000) articulated a clear recognition that the transition to online T\&L would involve more than just the development of new technical skills and that online development and delivery requires new pedagogical approaches. As Norton et al. (2013) also suggested, "training staff to use technology effectively ... requires significant time and resources. Without it, capital investments in technology will be wasted" (p. 29). The practical reality is that academics, even with the very best of intentions, simply cannot spend all of their limited non-teaching time in professional development just to keep up with the technology. And keeping up with the technology is not the only impediment to online T\&L. The following discussion highlights the change and challenge that academics face.

\section{Change \& Challenge}

Academics are traditionally responsible for managing their own timelines and most, if not all, ultimately "come up with the goods." Project managers are not in a position to re-prioritise the work priorities of academic staff nor to pull them away from other work commitments. Nor would their unit development necessarily be successful were this to occur. Again, the transition to online development is not a "one off" occurrence but a process of integration into the academics' own work practices (Ellis, Ledgerwood \& Phelps, 2000, p. 7).

It would also seem that not all staff are quite as enthusiastic about or embracing of new technologies and the changes that those technologies present (Wilson \& Stacey, 2004). This is to some extent understandable for academics and institutions steeped in the centuries-old traditions of face-to-face teaching. As noted by Anderson (2008), online learning presents challenges to educators partly because of its fluid and changing contextual state. This reinforces Wilson and Stacey's (2004) view that, "staff do not embrace change at the same pace, or in the same way, with some more reluctant than others to adopt new technologies into their practice" (p. 8).

Notwithstanding the adoption of/resistance to the rapidly changing nature of T\&L, there are, according to Anderson (2008), some pedagogical fundamentals of which we should not lose sight, including design and organisation, facilitating discourse, and direct instruction. The fundamentals of effective pedagogy remain valid. Whilst the technology is new, the pedagogical goals are old and it is not the medium of delivery that determines quality, what matters is the manner in which technology is used for learning (Norton et al., 2013) - which does not appear to have been quite as radical or revolutionary as initially assumed. Coaldrake and Stedman (2013) explained that:

Despite being two decades into the "internet age," online delivery has not done away with the physical university. ... Instead the use of websites, animations, podcasts, online videos and other tools has augmented face-toface approaches, and it is clear that we are only beginning to tap into the 
possibilities for using new media and technology in productive and effective ways. (p. 134)

And it was indeed upon these principles of quality pedagogy, irrespective of the delivery content, context or device, that REdelivery was developed, in a manner which was not - in reality or perception - either overbearing or compulsory. In the face of increasingly bureaucratic demands on their time, academics highly value and are justifiably protective of their autonomy, self-management and discretionary decision-making in order to remain engaged and effective (Ellis \& Phelps, 2000, p.7). In REdelivery, this autonomy would ultimately extend to how each individual academic engaged with and incorporated their respective REdelivery outcomes - providing individualised and pedagogically productive unit development. It confirmed the view that "despite the hype around purely online education, the big question is not whether online courses will replace classrooms, but whether technology will drive the re-design of teaching and learning ... by blending technology and classroom teaching" (Norton et al., 2013, p. 1).

Thus, the challenge for teachers designing and organising the online learning context is to create a mix of learning activities that are appropriate to student needs, teacher skills and style, learning objectives of the program of study, and institutional technical capacity. Doing so within the ever-present financial constraints of formal education systems is a challenge that will direct online learning design and implementation for the foreseeable future (Anderson, 2008). The use then of visual media, particularly video, becomes a useful and strategic medium to meet these challenges.

\section{Visual Media}

Visual, screen-based media have become so much a part of our daily lives that as consumers our visual vocabulary and perception have become very sophisticated indeed. We have developed - consciously or otherwise - a certain expectation of visual quality. And, in the academic context, this expectation goes to the very heart of academic credibility.

Whilst basic video recording of lectures has been an integral part of tertiary T\&L for decades, I would strongly argue that a camera's locked-off wide shot of a 2 hour auditorium lecture is unlikely to be engaging on screen - irrespective of how well it may be presented live in the auditorium. Similarly, given the proliferation of webcams, a close-up shot on a grainy webcam, against a distracting messy office background with poor lighting and distorted, out-of-sync audio is, irrespective of the subject matter, equally unlikely to be either engaging or academically credible. This kind of low cost, poor quality online offering tends to diminish the quality and engagement of the interaction and therefore the students' learning experience. (Norton et al., 2013, p. 20). So the approach taken with REdelivery has been to adapt both presenter and their content to and maximise the attributes and benefits of the screen medium for the academic context. 
Television is a very literal medium. This is illustrated every evening through television News during which a studio-bound "anchor" will invariably throw to a reporter on location, positioned on the site of the train wreck, the war zone, the dodgy used-car yard, the stormwater drain with rescued kitten. We have become accustomed to and unconsciously anticipate the contextual visuals reinforcing and showing the story. In the academic context it follows therefore that, for an engineering lecture about bridge design, it is perfectly reasonable to stand in front of an actual bridge to contextualise that. The logic of using a recording studio's semi-lit control room with its array of buttons, faders and speakers to provide a recognisable context to teach audio recording, is inescapable. The visual context provides instantly - even before the lecturer has spoken a word - both visual interest and immediately relevant visual cues linked to the lecture content supporting the lecturer's words. However, whatever the subject, wherever the location, and whoever is imparting the information, the most fundamental need is to "keep it human." This - as discussed in the following section - has been and continues to be the central principle, priority and focus of REdelivery.

\section{Keeping it human}

Irrespective of the visual cues contained within the frame, if the academic in the foreground of that frame is visibly uncomfortable and unconfident being there then no amount of graphics or green-screen technology is likely to make the T\&L interaction either engaging or pedagogically valid. As noted by Wilson and Stacey (2004):

... [in order to satisfy the] expectations of learners for an interactive online environment that engages them. ... The teacher's understanding in structuring and facilitating interaction through such a web environment requires effective staff development for them to be confident and competent online teachers. (pp. 33-34, emphasis added)

Just because someone is an outstanding teacher in the live face-to-face auditorium situation, it does not automatically follow that their content will be equally engaging on a matchbox-sized Smartphone screen. Even those non-neophobic lecturers who embrace technology are not necessarily equipped to instantly translate, transpose and, literally, reframe either themselves or their T\&L materials into the bite-sized-chunks demanded by the medium, without significant rethinking, repackaging and retraining. As Kenny, Quealy and Young (2002) suggested, "merely translating what is done in the face-to-face environment will not work" (p. 4). Wilson and Stacey (2004) paralleled this sentiment, observing that teachers confronted with the new technologies need to explore new ways of designing courses and resource materials for this new, unfamiliar, online teaching environment.

And whilst tertiary institutions have invested heavily (and continue to do so) in the technological aspects of online T\&L, there does not appear to have been a commensurate investment in the "human" aspects of using the technology.

Despite the recognition that teaching and learning materials need to be adapted for 
and to the onscreen medium, little attention appears to have been paid thus far to the actual people who are delivering it - who equally need to "adapt themselves" to that medium - in order to maximise the benefit of the technology by maximising the human communication skills of those using it. And in the exponential scramble to adopt new technologies, academics are in danger of being either forgotten by their institutions or fearing the "spectral threat of technologydriven obsolescence" (Coaldrake \& Stedman 2013, p. 3) - in the race to the online, digital, technological T\&L summit. Not being left behind or simply overwhelmed requires a dedicated commitment from both parties. As Kenny et al. (2002) suggested, developing engaging quality online learning courses needs an investment beyond the normal continuous improvement process of the University. It needs dedicated time, resources and specialist input.

In the face of high-tech high-expectations, academics need to not lose sight of their fundamental humanity - who we are within our professional processes and interactions. And, in maintaining that humanity, what is most often lost in the locked-off wide shot of a lecturer in the far auditorium distance, and what is always lost in an "information-only" download of readings, references, hyperlinks, slides and graphics, is the opportunity to harvest the subliminal signals (Bragg, 1995) that the body language and the personal engagement of the lecturer provides. We are thus deprived of the visible subtleties, nuance and depth of knowledge of and passion for their subject. As Anderson (2008) explained:

Online learning can present challenges to educators, as the tools and opportunities to discover students' preconceptions and cultural perspectives are often limited by bandwidth constraints, which limit the users' view of body language and paralinguistic clues. (p. 47)

Dry as some information might be, an accounting lecturer's passion for "a beautiful set of numbers" or the palpable sense of gratification of a reconciled balance sheet, can make the difference between student engagement, comprehension and retention, and a tedious, tiresome, detached (non)interaction. The keys to "keeping it human" are engagement and confidence and credibility.

\section{Engagement}

Not all screen-based T\&L embodies the kind of engagement which is fundamental to a positive interaction between lecturer and student. A principal imperative for REdelivery therefore was to retain accessibility, engagement, and pedagogical validity. Not just be convenient and cost-effective. The initiative was based on the idea that "student engagement is central to effective practice at the tertiary level...instruction must strive to engage them... An engaging use of technology beyond the simple transfer of traditional teaching methods online - is essential" (Norton, et al., 2013, pp. 20, 22).

In order to achieve this engagement, the lecturer needs to be comfortable, confident, and therefore credible within this new and different visual medium. It is indeed, as Wilson and Stacey (2004) suggested, a new and different role for 
academic staff. Thus, for REdelivery, achieving both "human-ness" and engagement, some sub-objectives needed to be considered:

- to enable the on-camera/online educational experience to work more effectively for both lecturer and student; and,

- to reach the point at which the lecturers become familiar and comfortable enough with the medium to themselves identify the potential for delivering their T\&L electronically.

The principal focus therefore was to work with the lecturers, the content experts, to enable them to become more comfortable, confident and credible within the visual medium - to repackage their information so as to engage with the students in a different, but still personal and personable way. To take them beyond the "bread-and-butter" grainy webcam screen-based material and create effective, engaging, personable pieces to camera which would provide the best T\&L interactions whilst functioning equally effectively across a diversity of digital devices.

Massingham and Herrington (2006) contended that:

If technology is used to mirror and perpetuate traditional forms of pedagogy such as acting as a repository of factual ... information then at best it will be used as a poor alternative to lectures. ... On the other hand, the affordances of technology can provide the tools for creating authentic learning environments and fostering the communication channels that support the social construction of knowledge and understanding. (p. 98) In order to create those authentic communication channels in the online context, the most fundamental ingredient is confidence - in oneself, one's content, and the medium.

\section{Confidence \& Credibility}

Highly intelligent, knowledgeable and articulate academics are essentially no different from any other group of people when it comes to issues of personal insecurities, self-esteem and self-confidence. Hence there were, predictably, differing levels and degrees of confidence to accommodate in REdelivery. Not in terms of academic knowledge but in actually presenting that knowledge in the oncamera environment which invariably feels unnatural and intimidating. One workshop participant in 2013 shared that:

At first speaking to the camera can be daunting, especially in public places. ... It was a challenge recording a piece to camera...It was good to be taken out of my comfort zone.

It is very rare indeed for anybody to spontaneously demonstrate a natural affinity for presenting to camera without some specific experience, professional development and/or coaching. Presenting to camera is a skill that, like any other, needs to be learned, practiced and refined in order to develop proficiency, presence and confidence. There is wisdom in the view that:

It is unrealistic to expect that this...experience will simply descend upon [the presenter] or instantaneously emerge organically...they need 
guidance, direction, performance confidence...they are not actors... and if they try to "act", or be someone that they are not, they will simply not come across as genuine...they are not being "authentic."

(Willems, 2009, p. 23)

I contend that on-camera confidence and presence are derived from the following:

- being conversant with the basics of the screen environment and terminology

- detailed, in-depth, fluent knowledge of one's materials

- appropriate adaptation and repackaging of those materials for the oncamera context

- detailed preparation and rehearsal

- fundamental ability to project one's personality through that inanimate, unresponsive piece-of-glass

Confidence-building, academic credibility, and personal authenticity were thus central motives and motivators for REdelivery. Because the integration of physical awareness, conscious control, "taking command of the space," establishes authority and influence on perceptions - both internal and external - developing increased confidence which then positively feeds on itself (Willems, 2009, p.41). This goes to the very heart of academic credibility. Students do not want to see a lecturer visibly uncomfortable on-camera, they want to see a confident, comfortable and therefore credible presenter imparting the depth breadth and detail of their knowledge expertise and experience.

\section{Redelivery professional learning}

The professional learning provided through the REdelivery program were workshops involving shooting a video.

\section{Workshops}

In order to develop this confidence a series of short workshops in presenting tocamera were convened. These workshops would:

- offer those academics unfamiliar with presenting to-camera an opportunity to initially "have a go" in a low-stress environment, therefore...

- assist academics to become more confident in front of the camera, also...

- provide a sense of which T\&L materials might best suit repackaging/adapting, hence...

- assist academics to adapt those T\&L materials, and therefore...

- save time in one-to-one recording sessions

The workshops were half-day, informal sessions - a "road test" for academics to explore and become more comfortable and confident in/with the medium. In addition, applying the principal of safety-in-numbers, the small group situation enabled individual attention whilst simultaneously moderating the intensity of the one-to-one experience. Ellis and Phelps (2000) suggested that: 
Managing academics is analogous to herding cats... the academic culture is one where academics are more open to self-management than external management...where people with key skills and abilities need large measures of autonomy and discretion to be effective in their work. (p. 7)

At the risk of disenfranchising academics with yet another professional development workshop in their busy and demanding lives - once the eyes have stopped rolling at the prospect - the workshops proved to be highly valuable for both the academics involved and the REdelivery team. As noted in an unpublished project update (March 27, 2013), the workshops proved to be even more crucial than first anticipated, and became a prerequisite to shooting a REdelivery video, as workshop "graduates" came much better prepared in terms of content and confidence. The workshops achieved something arguably even more important from my own professional point of view by revealing what kind of approach to take with each academic as their own director/presenting coach.

This outcome was a crucial one, as it enabled me to be prepared to be appropriately flexible, supportive and conduct some "soft" coaching of academics on the one-to-one filming day. This can be a very sensitive issue for academics who are used to being entirely in control in front of their students. This in itself placed significant pressure (mostly self-imposed) on each academic to confidently and credibly "come up with the goods" in a minimum number of takes. As a firm believer in Experiential Learning, my other overarching rationale for conducting the workshops was to allow academics the opportunity to discover their own hidden talents and abilities which are often buried deep and not immediately apparent, even to the person themselves (Robinson, 2010). The workshops provided that confluence of circumstances through which academics could, with some gentle mentoring, discover and tease out those untapped talents.

In addition to individual to-camera development, the workshops' collegial value cannot be overstated. As Ellis and Phelps (2000) noted, staff development workshops present opportunities for staff to learn together in a mutually supportive group, which develops a sense of cohesiveness and is immensely valuable - a collaborative approach which encourages cross-fertilisation of ideas and the sharing of experiences. This mutually supportive collegiality encouraged and enhanced the individual academics' confidence and was of enormous value. Lecturers responded positively about the workshops (as can be noted in the following narrative of Academic X). Formal and informal feedback was positive. 


\section{The Shoots}

Subsequent to the workshops a number of academics representing a broad crosssection of disciplines (see Figure 1), schools, topics and approaches were videorecorded. Without exception, those who had participated in the workshops came most prepared.

\begin{tabular}{|c|c|c|}
\hline Architecture & Fashion & Landscape Architecture \\
\hline $\begin{array}{c}\text { Creative Writing \& } \\
\text { Literature Studies }\end{array}$ & Industrial Design & Music \\
\hline Dance & Interactive \& Visual Design & Scientific Writing \\
\hline Drama & Interior Design & Typography \& Illustration \\
\hline Entertainment Industries & Journalism, Media \& & Visual Arts \\
\hline
\end{tabular}

Figure 1. Disciplines/courses represented in video presentations

The range and variety of outputs, adaptability and applications of the video shoots is perhaps best illustrated by the "REdelivery Trailer" video ${ }^{2}$. However, one of the most interesting outcomes of these videos was the unanticipated way in which one particular academic responded to, interacted with, and ultimately used REdelivery. The story of Academic $\mathrm{X}$ is told in the following narrative.

\section{Narrative: Academic “ $X$ ”}

As the result of a misdirected phone call, I found myself in conversation with an academic who was unknown to me. During the course of the conversation, I provided a précis of both REdelivery and my own role in that initiative.

$X$ 's immediate response was that their particular unit - Landscape Architecture demanded traditional face-to-face lectures as well as supervised field trips examining topography and landforms. Despite my best efforts, $X$ remained firmly of the view that they saw little purpose in being involved in REdelivery. Fast forward some three months, and Academic X has, over a chronologically short but deeply immersive journey from sceptic to workshop participant to practitioner to innovative implementer and ultimately REdelivery advocate, created some 20 REdelivery videos which have been integrated into both online and traditional F2F lectures.

Whilst unanticipated, this multi-purpose approach proved to be pedagogically rich, technologically interactive, highly engaging, blended learning. In anonymous formal surveys, Academic X's students commented:

- Better than field trip or lecture...

- Engaging and interesting.

\footnotetext{
${ }^{2}<$ https://mediawarehouse.qut.edu.au/QMW/player/?dID=24815\&dDocName=QMW_023690> Note: University Log in required.
} 
- Insightful...it was more effective because it was interactive and helped me understand ideas.

- It was a very interesting and interactive way of teaching... good to mix it up.

- Gave good insight into the different concepts ... gets you on-site and aids in the explanation of concepts.

The "blended" application of these REdelivery resources maximises their immediate relevance, re-usability and longevity - ultimately saving Academic X significant time and resources. Fieldwork becomes available to students without the logistical nightmares, time, costs, insurance implications and inconvenience of herding students onto buses. The "virtual fieldtrip" thus created, is supported by contextualised, detailed, referenced information, which encourages the students to follow-up on-site independently.

This complete transformation of Academic X's attitude towards and application of the use of technology was the catalyst which changed the attitudes of the students (Massingham \& Herrington. 2006), towards the delivery of this particular unit. In addition, the REdelivery approach demonstrates unequivocally that:

Unit development in an academic environment [is] complicated. There is no beginning and no end to the process. Any reputable educator will [be] constantly improving and updating in response to new literature and theories, changes in legislation, feedback from students and developing pedagogical ideas. Compounding this...is the technological dimension again, the committed online teacher will want to continue to develop their unit utilising new and more appropriate technology... online units cannot be perceived as a "product" but are in fact a "process" - a work in progress, with appropriate strategies established for ongoing refinement.

(Ellis, et al., 2000, p. 6)

Confidence developed through this T\&L success has transformed Academic X into a champion of the use of video/digital technology for pedagogical engagement. Their subsequent videos have continued to demonstrate not only the significant further development of personal/professional confidence and credibility, but also the development of a more acute visual perception and visual vocabulary, together with an appreciation of preparation, pre-visualisation and scripting appropriate to the screen/online medium - for both domestic and international student and stakeholder engagement.

Whilst this example represents perhaps the most significant and visible change and adoption of the medium and what it has to offer, other academics have similarly "made-the-leap," adopting and embracing to varying degrees the opportunities afforded by a new understanding and meaningful use of the medium. 


\section{Discussion}

From the outset REdelivery sought to involve the academics as closely and consultatively as possible, offering involvement on a voluntary basis. By acknowledging and respecting each academic's role as content experts, bringing to the process their own depth of knowledge, experience and expertise, any suggestion of compulsorily dictating what they should teach was never considered. However this new approach provided an opportunity to fine-tune academics' learning design, given the very different demands of online delivery.

Through the workshops, detailed discussion and coaching, every effort was made to enhance the "human" connection between academic and student through the digital medium - which is by its very nature remote and depersonalising. Countering that depersonalisation was a high priority for REdelivery. The workshops in particular became something of a litmus test for the kind of approach and interventions required in order for academics to become more comfortable, confident, and credible in this unfamiliar environment.

Feedback from academics and students confirmed that the principles of REdelivery present a way to move T\&L forward in the digital domain. Irrespective of its rapidly changing nature, "it is more likely that changes will involve adaptation and evolution rather than major dislocation" (Coaldrake \& Stedman, 2013, p. 248). The digital T\&L environment simultaneously presents challenges: logistical, curriculum, technical, academic - and opportunities: refreshing curriculum, reshaping learning, time-efficiency, flexibility/accessibility, enhanced engagement. Based upon the outcomes of REdelivery thus far, the opportunities demonstrably outweigh the challenges.

REdelivery continues to evolve and develop, as it should - a work in progress. A result of this ongoing evolution and refinement has been the emergence of a multi-purposeness. Whilst for some academics the notion of replacing face-to-face lectures completely represents a challenge to a worthy, reliable, long-standing tradition, for others it represents an opportunity to use the online environment as a productive conduit for presenting principles, practice and abstract concepts. Still others find that the direct integration of online footage into face-to-face lectures presents opportunities for greater interaction and engagement with the students.

At the very least REdelivery has prompted a good deal of reflection upon and rethinking of approaches to T\&L. From staff feedback, it became apparent that the project raised their awareness of new pedagogies and technologies, allowed them to try out and test new skills, to reconceptualise teaching and capitalise on the affordances of online technologies. One REdelivery workshop participant noted that:

I think I was very locked in before to thinking about lectures and tutorials as the standard model with a few workshops thrown in, and [Redelivery] has given me a chance to think about different approaches to both 
conveying content but also discussing procedures in teaching, and that's been really liberating. (June 19, 2013)

The individually tailored nature of REdelivery - and academics' response to and incorporation of its principles and processes - is further illustrated by evaluative comments of participating academics (from June 2013):

- REdelivery has really offered an opportunity to experiment. To explore how rich media content can be used in teaching and learning.

- Rethinking the activities and rethinking the online content ... I now have a lot more online content ... all due to thinking about how those videos would connect to that information online.

- The relationship between content and process, in that the content for the actual video needed to be abstract enough, needed to be at meta-level so that the students across a set of different units could then contextualise and ground that content.

- REdelivery has inspired me to seriously rethink my teaching practices ...to explore and experiment with blended and online delivery - to play with the possibilities

- As REdelivery has evolved there has been a range of outcomes, some predictable, others unanticipated, but all productive and instructive, demonstrating the importance of the adaptation and integration of content quality, academic credibility, human engagement, visual vocabulary, and aesthetics. There seems to be an almost infinite number of applications for REdelivery, depending upon which particular academic teaches which particular unit within which particular discipline.

REdelivery represents a compelling case for and clear illustration of "research through teaching," and conversely, "teaching through research," confirming the proposition put by Coaldrake \& Stedman (2013) that "research and teaching are inextricably linked" (p. 8). The continued exploration of this notion requires ongoing support and investment of resources, time and collaborative expertise, for academics to maximise their T\&L interactions, and to engage with, comprehensively educate, and retain their students in the digital context.

\section{Conclusion}

There is a diagnostic element to working with academics or indeed any presenter. One needs to discreetly assess, within a few seconds, the general level of confidence embodied within and emanating from a person in order to sensitively and productively proceed. At the risk of generalisation, with REdelivery we were dealing with intelligent, articulate, mature-age, high achievers, whose personalities have evolved through a liberal dose of life experiences. Given that, each person possesses utterly unique, unstated, unconscious and complex levels of 
residual effects on their personalities and hence inherent levels of confidence (or not) which are in turn distilled, made manifest, and magnified through the camera. This diagnostic aspect attended to "how that unique physical personality manifests itself in the presentation context and how to stylise and maximise its benefits, rather than pretend it's not there" (Willems, 2009, p. 22).

Whilst certainly not a psychologist - either qualified or "pop" - coaching academics and/or presenters is a role which by its nature demands a combination of fine-grained perception, human sensitivity, delicate diplomacy, assertive direction and encouragement to "take risks." One does not need to be a qualified psychologist to demonstrate sensitivity in order to minimise the stress experienced in a fundamentally stressful environment, whilst simultaneously encouraging those with less confidence to push themselves beyond their usual risk-taking boundaries. Invariably the vast majority of participants acknowledged the value of having been pushed a little beyond their comfort zone and find the experience difficult but valuable. One participant (May 2012) commented that:

Empowering - you made us step out of our comfort zone by completing challenging exercises...very daunting and uncomfortable, [but] unfortunately there's no other way to learn and receive honest and constructive feedback.

Taking participants supportively out of that comfort zone requires some delicate handling and brings with it a responsibility to build rather than destroy selfconfidence by pushing academics just the right amount without the pushing being apparent. Maintaining a non-confronting, personable, generous and interactive environment is essential for success, as is the use of humour - all vital ingredients which lighten the situation and ease some of the (typically self-imposed) pressure on the academic.

I refer to this as "professional development by stealth."

\section{References}

Anderson, T. (2008). Towards a theory of online learning. In T. Anderson (Ed.), Theory and Practice of Online Learning (pp. 45-74). Edmonton, Canada: AU Press.

Bragg, M. (Interviewer). (1995, February 12). “Jonathan Miller”. In The South Bank Show [Television broadcast]. London: ITV.

Caplan, D., \& Graham, R. (2008). The development of online courses. Anderson, T. (2008). Towards a theory of online learning (pp. 245-263). In T. Anderson (Ed.), Theory and Practice of Online Learning. Edmonton, Canada: AU Press.

Coaldrake, P., \& Stedman, L. (1999). Academic work in the twenty-first century. Occasional Paper Series 99H. Canberra, Australia: Department of Education, Training and Youth Affairs (DETYA).

Coaldrake, P., \& Stedman, L. (2013). Raising the stakes: Gambling with the future of universities. Brisbane, Australia: University of Queensland Press. 
Coomey, M., \& Stephenson, J. (2001). Online learning: It is all about dialogue, involvement, support and control - according to the research. In J. Stephenson (Ed.), Teaching and learning online: Pedagogies for new technologies (pp. 37-52). London: Kogan Page.

Ellis, A., \& Phelps, R. (2000). Staff development for online delivery: A collaborative, team based action learning model. Australian Journal of Educational Technology, 16(1), 26-44. Retrieved from http://www.ascilite.org.au/ajet/ajet16/ellis.html

Hubbs, D.L., \& Brand, C.F. (2005). The paper mirror: Understanding reflective journaling. Journal of Experiential Education, 28(1), 60-71.

Kenny, J., Quealy, J., \& Young, J. (2002). RMIT ICT DLS Competency Framework - A basis for effective staff development. Retrieved from http://trove.nla.gov.au/work/153099420

Massingham, P., \& Herrington, T. (2006). Does attendance matter? An examination of student attitudes, participation, performance and attendance. Journal of University Teaching \& Learning Practice, 3(2). Retrieved from http://ro.uow.edu.au/jutlp/vol3/iss $2 / 3$

Norton, A., Sonnemann, J. \& McGannon, C. (2013). The online evolution: When technology meets tradition in higher education. Grattan Institute Report No. 2013-3, April 2013. Retrieved from http://grattan.edu.au/report/the-online-evolution-whentechnology-meets-tradition-in-higher-education

Phelps, R., Ledgerwood, T., \& Bartlett, L. (2000). Managing the transition to online teaching: The role of project management methodology in the learning organisation. In Proceedings, Moving online: a conference to explore the challenges of workplaces, colleges and universities (pp. 203-216), August 18-19, Gold Coast, School of Social and Workplace Development, Southern Cross University, Lismore, Australia.

Phillips, R., Gosper, M., McNeill, M., Woo, K., Preston, G., \& Green, D. (2007). Staff and student perspectives on web-based lecture technologies: Insights into the great divide. In Proceedings ASCILITE Singapore 2007, ICT: Providing choices for learners and learning. Retrieved from http://www.ascilite.org.au/conferences/singapore07/procs/phillips.pdf

Robinson, K. (2010). The Element - RSA Presentation. Retrieved from http://www.youtube.com/watch?v=3TAqSBMZDY8 accessed 26/06/2013

Tynan, B., Ryan, Y., Hinton, L., \& Lamont Mills, A. (2012). Out of hours - Final Report of the project e-Teaching leadership: Planning and implementing a benefits-oriented costs model for technology enhanced learning. Australian Learning \& Teaching Council. Retrieved from https://eprints.usq.edu.au/21319/2/Tynan_Ryan_Hinton_Mills_LRTC_2012_PV.pdf

Wilson, G., \& Stacey, E. (2004). Online interaction impacts on learning: Teaching the teachers to teach online. Australasian Journal of Educational Technology, 20(1), 3348.

Willems, C. H. (1997). Technological challenges: Aesthetic solutions. Unpublished Masters thesis. Academy of the Arts, Queensland University of Technology, Brisbane. Retrieved from https://eprints.usq.edu.au/673/2/Willems_02whole_masters_thesis.pdf

Willems, C. H. (2008). VODcasts and commentary. Music, Mime \& Metamorphosis (Doctoral Project 2). Unpublished Doctoral thesis, Creative Industries Faculty, 
Queensland University of Technology, Brisbane. Retrieved from http://eprints.qut.edu.au/37953/3/Project2MMM091012.pdf

Willems, C. H. (2009). Stylised Version of You ${ }^{\circledR}$. Music, Mime \& Metamorphosis (Doctoral Project 3). Unpublished Doctoral thesis, Creative Industries Faculty, Queensland University of Technology, Brisbane. Retrieved from http://eprints.qut.edu.au/37953/4/Project3STYLISED090909.pdf

Copyright ( 2015 Christiaan Willems 